\title{
Erratum to: PI3K/Akt/mTOR signaling in medullary thyroid cancer: a promising molecular target for cancer therapy
}

\author{
Gloria Irene Manfredi ${ }^{1}$ - Alessandra Dicitore ${ }^{2}$ Germano Gaudenzi ${ }^{1}$. \\ Michele Caraglia $^{3}$. Luca Persani ${ }^{1,2}$ - Giovanni Vitale ${ }^{1,2}$
}

Published online: 8 July 2016

(c) Springer Science+Business Media New York 2016

Erratum to: Endocrine (2015) 48:363-370 DOI: 10.1007/s12020-014-0380-1

Unfortunately, the original publication of the article contained an error in the affiliation section. The correct affiliation for authors A. Dicitore, L. Persani and G. Vitale should be Laboratory of Endocrine and Metabolic Research, Istituto Auxologico Italiano IRCCS, Via Zucchi 18, Cusano Milanino (MI), 20095 Milan, Italy.

This has been corrected with this erratum.

The online version of the original article can be found under doi: 10.1007/s12020-014-0380-1.

$\checkmark$ Giovanni Vitale

giovanni.vitale@unimi.it

1 Department of Clinical Sciences and Community Health, University of Milan, Milan, Italy

2 Laboratory of Endocrine and Metabolic Research, Istituto Auxologico Italiano IRCCS, Via Zucchi 18, Cusano Milanino (MI), 20095 Milan, Italy

3 Department of Biochemistry, Biophysics and General Pathology, Second University of Naples, Naples, Italy 